\title{
A Sensitive Method for the Rapid Determination of Underivatized Ethyl Carbamate in Fortified Wine by Liquid Chromatography-Electrospray Tandem Mass Spectrometry
}

\author{
João M. Leça ${ }^{1,2}$ • Vanda Pereira ${ }^{1,2}$ (1) A Ana C. Pereira ${ }^{1,3}$ • José C. Marques ${ }^{1,2}$
}

Received: 17 April 2017 / Accepted: 14 July 2017 /Published online: 15 August 2017

(C) Springer Science+Business Media, LLC 2017

\begin{abstract}
This work presents the optimization of a miniaturized liquid-liquid extraction (mLLE) followed by reversed-phase liquid chromatography-electrospray tandem mass spectrometry (RP-HPLC-MS/MS) for the determination of ethyl carbamate (EC) in fortified wine, without using derivatizing agents. The mLLE was optimized by an experimental design. Thus, $15 \mathrm{~mL}$ of wine and $8 \mathrm{~mL}$ of ethyl acetate were used for the extraction. After concentration, each extract was injected into the HPLCMS/MS equipment and the characteristic secondary ion transition of EC $(\mathrm{m} / \mathrm{z}=90.10 \rightarrow 62.05)$ was used for the quantification purposes. The proposed method presented a good linearity $\left(R^{2}=0.9999\right)$ and a high sensitivity with low limits of detection (LOD) and quantification (LOQ), 0.17 and $0.52 \mu \mathrm{g} \mathrm{L}^{-1}$, respectively. The precision (repeatability and reproducibility) never exceeded $8 \%$ of variation, and the recoveries varied between 93 and 114\%. The applicability of the method was checked through the analysis of 24 fortified wines, with EC values ranging between $23 \pm 1$ and $194 \pm 5 \mu \mathrm{g} \mathrm{L}^{-1}$. All chromatograms revealed good peak resolutions. This new method is efficient for the simple, fast, and reliable determination of EC in fortified wines, providing great sensitivity without using derivatizing agents or large volumes of organic solvents.
\end{abstract}

Vanda Pereira

vpereira@uma.pt

1 Faculty of Exact Sciences and Engineering, University of Madeira, Campus da Penteada, 9020-105 Funchal, Portugal

2 Institute of Nanostructures, Nanomodelling and Nanofabrication (I3N), University of Aveiro, Aveiro, Portugal

3 CIEPQPF, Department of Chemical Engineering, University of Coimbra, Pólo II - Rua Sílvio Lima, 3030-790 Coimbra, Portugal
Keywords Ethyl carbamate $\cdot$ Liquid-liquid extraction . Wine $\cdot$ Liquid chromatography-mass spectrometry $\cdot$ Design of experiments

$\begin{array}{ll}\text { Abbreviations } \\ \text { EC } & \text { Ethyl carbamate } \\ \text { mLLE } & \text { Miniaturized liquid-liquid extraction } \\ \text { LC } & \text { Liquid chromatography } \\ \text { MS/MS } & \text { Tandem mass spectrometry } \\ \text { MRM } & \text { Multiple reaction-monitoring } \\ \text { FW } & \text { Fortified wine } \\ \text { DoE } & \text { Design of experiments } \\ \text { IS } & \text { Internal standard } \\ \text { ME } & \text { Matrix effect } \\ \text { LOD } & \text { Limit of detection } \\ \text { LOQ } & \text { Limit of quantification }\end{array}$

\section{Introduction}

Ethyl carbamate (EC), also known as urethane (PubChem CID 5641), is the ethyl ester of carbamic acid that is formed in fermented foods and beverages, namely fortified wines, by the reaction of nitrogen compounds with ethanol (JECFA 2005). It is recognized as a toxic compound and was reclassified in 2007 by the International Agency of Research on Cancer (IARC) as probably carcinogenic to humans (group 2A) (Baan et al. 2007). The most relevant pathways for the formation of $\mathrm{EC}$ in alcoholic beverages have already been identified. The chemical family of EC's main precursors are cyanide and carbamoyl compounds, namely urea, carbamoyl phosphate, citrulline, and hydrogen cyanide (Jiao et al. 2014). In wines, EC is mainly formed during and after fermentation, by the reaction of carbamoyl compounds with ethanol. The 
most common way for EC to occur in acidic medium, such as wine, is the reaction of ethanol with urea. Urea and citrulline are both derived from the arginine metabolism during the fermentative processes (Arena et al. 1999; Stevens and Ough 1993; Weber and Sharypov 2009). External factors, such as temperature and $\mathrm{pH}$ influence the kinetics of these reactions (Jiao et al. 2014; Weber and Sharypov 2009). Its formation is also associated with storage time (Hasnip et al. 2004).

Canadian authorities, based on a study about EC toxicity, investigated by Schmahl et al. (1977), imposed for the first time, in 1985, legislation regulating the EC limit values in alcoholic beverages. Until now, a common legislation to regulate the maximum level of EC (EFSA 2007) has not been established in the European Union. However, some countries have established their own legislation. For example, in regard to fortified wines, the Czech Republic implemented an identical legislation to that of Canada, $100 \mu \mathrm{g} \mathrm{L}^{-1}$, while the USA are more restrictive with a limit of $60 \mu \mathrm{g} \mathrm{L}^{-1}$ (Weber and Sharypov 2009). The concerns raised by the toxicological aspects and the low concentration levels of EC found in alcoholic beverages have motivated several researchers to improve its analytical quantification (EFSA 2007; Weber and Sharypov 2009).

Gas chromatography coupled with mass spectrometry (GC-MS) has become the most used technique for the quantification of EC and propyl carbamate, while butyl carbamate (BC) and EC labeled with deuterium $\left({ }^{13} \mathrm{C}\right.$ or ${ }^{15} \mathrm{~N}$ isotopes) have been used as internal standards (IARC 2010; Weber and Sharypov 2009). Different approaches have been used to extract EC before the chromatographic separation. The official method of the International Organization of Vine and Wine involves a complex and time-consuming extraction procedure, using a diatomaceous earth solid-phase extraction column, prior to the GC-MS analysis (Bertrand and Hitos 1998). Thus, several efforts have been done to develop methodologies to determine $\mathrm{EC}$ without using long procedures and laborious analyses, combining precision and high sensitivity. In this regard, headspace solid-phase microextraction (HSSPME) has been gaining great highlight (Lachenmeier et al. 2006; Perestrelo et al. 2010; Whiton and Zoecklein 2002). More recently, ultrasound-assisted emulsificationmicroextraction (USAEME) and microextraction by packed sorbent (MEPS) have also been reported as feasible and easy-to-use extraction techniques to determine EC in alcoholic beverages (Leça et al. 2014; Liao et al. 2013).

The LLE methods found in literature to determine EC use significant volumes of sample and organic solvents along with time-consuming extraction procedures or derivatization agents. Fauhl and Wittkowski (1992) determined EC by continuous LLE through a Soxhlet apparatus followed by GC-MS analyses. Most recently, EC derivatized with bis(trimethylsilyl)trifluoroacetamide was extracted by LLE and quantified by GC-MS (Xu et al. 2012). Valente et al. (2014) used salting-out assisted LLE to analyze
EC derivatized with 9-xanthydrol followed by a highperformance liquid chromatography with fluorescence detection. These have emerged as an attempt to improve the methods used for EC determination.

The aim of this study was the development of a simple, efficient, and sensitive method to quantify EC in fortified wines, without using derivatizing agents, minimizing the reagent consumption, and reducing the use of toxic organic solvents, through the optimization of a mLLE procedure combined with reversed-phase liquid chromatographyelectrospray tandem mass spectrometry (RP-HPLC-MS/MS).

\section{Materials and Methods}

\section{Chemicals and Samples}

Ethyl carbamate (EC) was purchased from Acros Organics (Geel, Belgium), while butyl carbamate (BC), used as internal standard (IS), was obtained from Sigma-Aldrich (Steinheim, Germany). All standards had a purity grade higher than $97 \%$. Absolute ethanol was purchased from Sigma-Aldrich, tartaric acid, formic acid, and methanol (UPLC grade) were from Panreac (Barcelona, Spain), and ethyl acetate was from Fisher Scientific (Leicestershire, UK). Ultra-pure water (type 1) was obtained from a Simplicity® UV apparatus from Millipore (Milford, MA, USA). Ethyl carbamate and BC $1 \mathrm{~g} \mathrm{~L}^{-1}$ stock solutions were rigorously prepared in ultra-pure water. Intermediate solutions of $50 \mathrm{mg} \mathrm{L}^{-1}$ in EC and $10 \mathrm{mg} \mathrm{L}^{-1}$ in $\mathrm{BC}$ were prepared in order to obtain the calibration solutions, which were then used to spike the synthetic wine (containing $6 \mathrm{~g} \mathrm{~L}^{-1}$ of tartaric acid, $18 \%$ of ethanol, and $\mathrm{pH}$ adjusted to 3.5 , with a $1 \mathrm{M} \mathrm{NaOH}$ solution). Each calibration point was extracted in duplicate and injected twice, within the validation range $1.0-200 \mu \mathrm{g} \mathrm{L}^{-1}$. To test the method applicability, a sample set of 24 fortified wines, with different ages (up to 86 years old) and ethanol content between 18 to $20 \%$, were analyzed.

\section{Apparatus and Chromatographic Conditions}

A Nexera X2 UHPLC system (Shimadzu, Kyoto, Japan) consisting of binary LC-30AD pumps, a DGU-20 A5 degassing unit, a CTO-20A column oven, and a SIL-30AC autosampler was used. The LC system was coupled with the Shimadzu triplequadruple mass spectrometer LCMS-8040, equipped with an ESI ionization module. Sample extracts were separated in the reversed-phase mode (RP) using a Kinetex C18 column, $150 \times 2.1 \mathrm{~mm}, 2.6 \mu \mathrm{m}, 100 \AA$, from Phenomenex (Torrance, CA, USA) thermostated at $40{ }^{\circ} \mathrm{C}$. The injection volume was $5 \mu \mathrm{L}$ and all samples were injected twice. A gradient elution with methanol (solution A) and ultra-pure water with $0.1 \%$ of formic acid (solution B) were used at a $0.4 \mathrm{~mL} \mathrm{~min}{ }^{-1}$ flow rate. The gradient started with the solution A maintained at 5\% for $4 \mathrm{~min}$ 
and then increased to $30 \%$ in $2 \mathrm{~min}$, then to $100 \%$ in $1 \mathrm{~min}$. Finally, solution A was reduced to 5\% in $3 \mathrm{~min}$ and held at 5\% for $5 \mathrm{~min}$ to prepare the next injection. All eluents were filtered through a hydrophilic polypropylene $0.2 \mu \mathrm{m}$ pore size membrane filter (Pall Corporation, Ann Arbor). The column effluent was directed to the detector between the 0.5 and $9.0 \mathrm{~min}$, and the rest was discarded. The LCMS-8040 ESI was operated in the positive ion mode along with multiple reaction-monitoring (MRM) mode, acquiring data for a single secondary ion transition $(\mathrm{m} / \mathrm{z}=90.10 \rightarrow 62.05)$ for $\mathrm{EC}$ and $(\mathrm{m} / \mathrm{z}=118.00 \rightarrow 62.05)$ for $\mathrm{BC}$, with an optimal collision energy of -10 and $-9 \mathrm{eV}$, respectively. The desolvation line temperature was maintained at $250{ }^{\circ} \mathrm{C}$ and the block heater at $400{ }^{\circ} \mathrm{C}$; the nebulizing gas flow was $2.5 \mathrm{~L}$ $\mathrm{min}^{-1}$ and the dying gas flow was $17.5 \mathrm{~L} \mathrm{~min}^{-1}$. The data acquisition and all peak integration processing were performed with the Labsolutions 5.7 software (Shimadzu).

\section{mLLE Optimization}

Ethyl acetate was chosen to develop the extraction procedure and was optimized by performing a full factorial design. Experimental design methodologies are increasingly more relevant in the optimization of quantification methodologies of various compounds, including EC (Leça et al. 2015, 2014; Machado et al. 2012; Zhang and Zhang 2008). To maximize the HPLC-MS/MS response of EC, two experimental variables, at three levels, were studied: the sample volume at 8,10 , and $15 \mathrm{~mL}$ and the extractant volume at 4 , 5 , and $8 \mathrm{~mL}$. All experiments were made varying the sample and extractant volumes in random order according to Table 1. A commercial fortified wine was used for the method optimization. The data analysis was performed using the Matlab software, version R2016b, to estimate the factorslevels combination that ensure the maximization of the HPLC-MS/MS response of EC.

\section{mLLE Optimized Procedure}

In $50 \mathrm{~mL}$ PTFE centrifuge tubes, $8 \mathrm{~mL}$ of ethyl acetate (extractant solvent) was added to $15 \mathrm{~mL}$ of sample/standard solution spiked with $50 \mu \mathrm{L}$ of internal standard $\left(10 \mathrm{mg} \mathrm{L}^{-1}\right.$ $\mathrm{BC}$ solution). After vigorous shaking in vortex for $5 \mathrm{~min}$, the tube was centrifuged at $4400 \mathrm{rpm}$ for $5 \mathrm{~min}$ to achieve the separation of the liquid phases. Finally, an aliquot of the upper phase was collected and evaporated using a small nitrogen flow. The residue was redissolved with mobile phase $B$ to a final volume of $1 \mathrm{~mL}$ and filtered through Chromafil PTFE $0.2 \mu \mathrm{m}$ syringe filters (Macherey-Nagel, Düren, Germany). Each sample/standard solution was extracted twice. Finally, $5 \mu \mathrm{L}$ of extract was injected twice into the HPLC-MS/MS system.
Table 1 Experiments of the full factorial design

\begin{tabular}{|c|c|c|}
\hline Number & $\begin{array}{l}\text { Sample volume } \\
(\mathrm{mL})\end{array}$ & $\begin{array}{l}\text { Solvent volume } \\
(\mathrm{mL})\end{array}$ \\
\hline 1 & 8 & 8 \\
\hline 2 & 15 & 4 \\
\hline 3 & 15 & 4 \\
\hline 4 & 8 & 5 \\
\hline 5 & 10 & 8 \\
\hline 6 & 10 & 8 \\
\hline 7 & 8 & 4 \\
\hline 8 & 8 & 8 \\
\hline 9 & 11.5 & 6 \\
\hline 10 & 8 & 5 \\
\hline 11 & 10 & 4 \\
\hline 12 & 10 & 5 \\
\hline 13 & 15 & 5 \\
\hline 14 & 8 & 4 \\
\hline 15 & 11.5 & 6 \\
\hline 16 & 10 & 5 \\
\hline 17 & 10 & 4 \\
\hline 18 & 15 & 5 \\
\hline 19 & 15 & 8 \\
\hline 20 & 15 & 8 \\
\hline
\end{tabular}

\section{Method Validation}

The mLLE/RP-HPLC-MS/MS method optimized for the determination of EC in fortified wines was validated in terms of selectivity, linearity, sensitivity, matrix effect, precision, and accuracy.

Selectivity was appraised by the analysis of five fortified wines to ensure the absence of chromatographic interferences at the retention time of $\mathrm{EC}(\mathrm{m} / \mathrm{z}=90.10 \rightarrow 62.05)$ and $\mathrm{BC}$ $(\mathrm{m} / \mathrm{z}=118.00 \rightarrow 62.05)$ which could compromise its quantification.

The working standard solutions were prepared by spiking synthetic wine at eight different concentration levels of EC 1, $2.5,5,12.5,25,50,100$, and $200 \mu \mathrm{g} \mathrm{L}^{-1}$ with a $50 \mu \mathrm{L}$ spike of $\mathrm{BC}\left(10 \mathrm{mg} \mathrm{L}^{-1}\right)$. The calibration curve was obtained by plotting the analyte peak area ratio ( $\mathrm{EC}$ area/BC area) against the corresponding EC concentration.

The linearity and sensitivity were determined based on the linear regression results. Linearity was determined by the coefficient of correlation, $R$-squared $\left(R^{2}\right)$, of the generated calibration curve. Sensitivity was evaluated by determining the limit of detection (LOD) and the limit of quantification (LOQ), as follows: $\mathrm{LOD}=3.3 \sigma / b$ and $\mathrm{LOQ}=10 \sigma / \mathrm{b}$, with $\sigma$ as the standard deviation of the $y$-intercept and $b$ the curve slope (Șengül 2016; Vial and Jardy 1999).

The matrix effect (ME) was assessed through the percentage of the quotient between the slopes of the curves 
obtained from the standards solutions in synthetic wine and the curves obtained by spiking a dry and a sweet fortified wines with the same concentration of EC, by the following equation (Dong et al. 2015; Dong and Xiao 2017; Matuszewski et al. 2003; Taverniers et al. 2004; Xian et al. 2016):

$\% \mathrm{ME}=\left[\frac{(\text { slope of fortified wine calibration curve-slope of synthetic wine calibration curve })}{\text { slope of synthetic wine calibration curve }}\right] \times 100$

Precision was estimated based on inter- and intra-day analyses of two standard solutions and one fortified wine. Intraday repeatability was assessed by the response of ten successive extractions. Inter-day reproducibility was assessed by the results of the analyses of five extractions of the same samples in three different days. These parameters were expressed as relative standard deviation (\%RSD).

The accuracy of the method was evaluated through a recovery study, by spiking a fortified wine in triplicate, with known amounts of $\mathrm{EC}$ at four representative concentration levels (25, 50,100 , and $200 \mu \mathrm{g} \mathrm{L}^{-1}$ ), within the calibration range. Recovery was calculated by comparing the mean values of the three replicates with the theoretical concentrations of each one.

The method was applied to 24 different fortified wines, with ages between less than 1 and up to 86 years old, in order to confirm the applicability of the proposed RP-HPLC-MS/ MS method for determining EC in fortified wines.

\section{Results and Discussion}

HPLC-MS/MS, combined with MRM, was selected for the quantification of EC in fortified wines due to its high loading capacity, sensitivity, and selectivity (Moein et al. 2016). The LC-MS/MS technique was previously used to quantify EC but typically with a derivatization step or other extraction techniques in sample preparation (Alberts et al. 2011; Deák et al. 2010). To optimize the analytical technique, a solution of EC and $\mathrm{BC}$ was directly injected into the HPLC-MS/MS equipment to determine their retention times, 1.9 and $7.8 \mathrm{~min}$, respectively. The optimal collision energy to quantify EC with $\mathrm{BC}$ as internal standard was defined through multiple tests, using the Labsolutions 5.7 software. The elution gradient was optimized with real samples to obtain the best separation and peak resolution.

\section{mLLE Method Optimization}

From the previously survey for solvents free of EC, by Leça et al. (2014), acetonitrile and ethyl acetate were selected, due to their lower density, to firstly perform a QuEChERS (quick, easy, cheap, effective, rugged, and safe) extraction procedure. The QuEChERS approach was first reported by Anastassiades et al. (2003) and is characterized as user-friendly, inexpensive, effective, robust, secure, and with high recoveries. This procedure was firstly chosen to extract the target compound from fortified wines since it has been widely applied to various classes of compounds in several matrices (Bruzzoniti et al. 2014). The influence of salts and buffers on the extraction yield was studied. Since they did not increase the extraction yield of EC, these were removed from the extraction procedure and the extraction was transformed into a mLLE, with the advantage of being cheaper and user-friendly. Acetonitrile and ethyl acetate were both tested. Ethyl acetate was chosen as the extractant solvent rather than acetonitrile, since it leads to chromatograms with less interferences and better peak shapes. Acetonitrile extracts increased background noise and originate interferences that coelute with EC peak.

To optimize the mLLE extraction, a full factorial design was carried out, considering two factors, the sample and extraction solvent volumes. The optimum conditions were those which maximize the EC chromatographic peak area in the HPLCMS/MS equipment. The full factorial design was done considering three levels per factor, namely the sample volume at 8,10 , and $15 \mathrm{~mL}$ and the extractant volume at 4,5 , and $8 \mathrm{~mL}$. The two variables analyzed revealed to be significant, as well as the interaction factor between them ( $p$ values lower than 0.05 ). As illustrated by Fig. 1, the maximum EC chromatographic peak area, for the mLLE method, can be achieved using $15 \mathrm{~mL}$ of fortified wine sample combined with $8 \mathrm{~mL}$ of ethyl acetate.

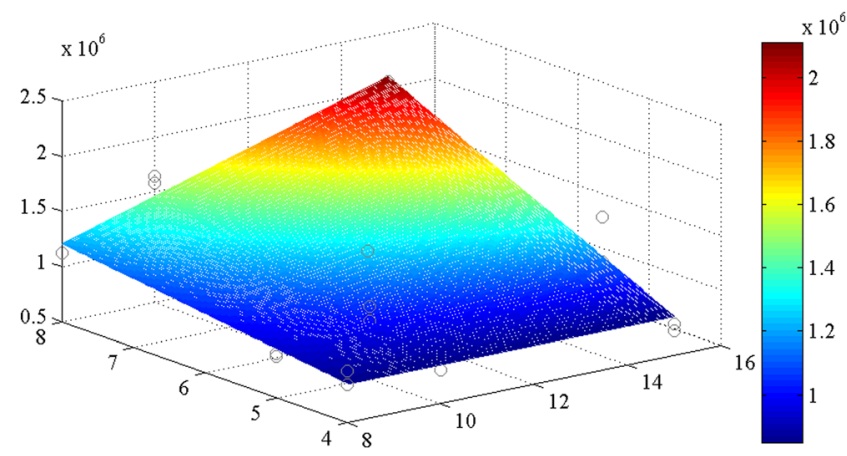

Fig. 1 Full factorial design to optimize the miniaturized LLE procedure with sample volume, extraction solvent volume, and the HPLC-MS/MS response as variables. The graphic illustrates the variation of the HPLC$\mathrm{MS} / \mathrm{MS}$ response 


\section{mLLE Method Validation}

The proposed mLLE/RP-HPLC-MS/MS method to quantify EC in fortified wines showed good selectivity, verified by the absence of interferences at $\mathrm{EC}$ and $\mathrm{BC}$ retention times in synthetic and real wine samples, as depicted in Fig. 2.

It is recognized that the matrix effect can compromise the results of an analytical method, especially when the intention is to analyze samples of high complexity, such as fortified wines. Thus, the coefficient of variation between the slopes of the synthetic wine calibration curve and those of the spiked dry and sweet fortified wines was 3.4 and $2.5 \%$, respectively (curves are almost parallel). These results show that the differences between the curves obtained using the synthetic and real wine matrices are negligible.

Table 2 summarizes the method validation results. A single calibration curve was generated by the average response of eight concentration levels, prepared in synthetic wine. Each level was represented by three extracts, injected twice. A good correlation coefficient was obtained, $R^{2}=0.9999$, confirming the linearity of the method. The LOD and LOQ results determined by the calibration curve, 0.17 and $0.52 \mu \mathrm{g} \mathrm{L}{ }^{-1}$, respectively, are close to and, in most cases, lower than those found in literature (Ajtony et al. 2013; IARC 2010; Jagerdeo et al. 2002; Lachenmeier et al. 2005; Lachenmeier et al. 2006; Leça et al. 2014; Mo et al. 2014; Perestrelo et al. 2010; Whiton and Zoecklein 2002; Xu et al. 2012; Zhang et al. 2014), conferring a good sensitivity to the
Table 2 Validation results obtained for the proposed mLLE/RP-HPLCMS/MS method

\begin{tabular}{ll}
\hline Parameter & Result \\
\hline Linear regression & $A_{\text {rel }}=0.1706[E C]+0.0438$ \\
Linear concentration range & $1.0-200 \mu \mathrm{g} \mathrm{L}^{-1}$ \\
$R^{2}$ & 0.9999 \\
$\mathrm{LOD}\left(\mu \mathrm{g} \mathrm{L}^{-1}\right)$ & 0.17 \\
$\mathrm{LOQ}\left(\mu \mathrm{g} \mathrm{L}^{-1}\right)$ & 0.52 \\
Recovery & $\%$ \\
$\mathrm{FW}+25 \mu \mathrm{g} \mathrm{L}^{-1}$ of EC & 93 \\
$\mathrm{FW}+50 \mu \mathrm{g} \mathrm{L}^{-1}$ of EC & 113 \\
$\mathrm{FW}+100 \mu \mathrm{g} \mathrm{L}^{-1}$ of EC & 113 \\
$\mathrm{FW}+200 \mu \mathrm{g} \mathrm{L}^{-1}$ of EC & 114 \\
\hline
\end{tabular}

$A_{\text {rel }}$ relative area (EC peak area/BC peak area), $[E C] \mathrm{EC}$ concentration in $\mu \mathrm{g} \mathrm{L}^{-1}, L O D$ limit of detection, $L O Q$ limit of quantification, $F W$ fortified wine, $E C$ ethyl carbamate

developed method. The LOQ result is about ten times more sensible when compared to the direct determination approach (LOQ = $5.0 \mu \mathrm{g} \mathrm{L}^{-1}$ ) used by Lijuan et al. (2012). The method also revealed a good repeatability (1.6-5.6\%) and reproducibility (2.1-8.0\%) and never exceeded 8\% of RSD. In turn, the results of the recovery study ranged between 93 and $114 \%$, as summarized in Table 2, demonstrating the accuracy of the method.

Regarding the applicability of the proposed mLLE/RPHPLC-MS/MS method for the determination of EC in fortified

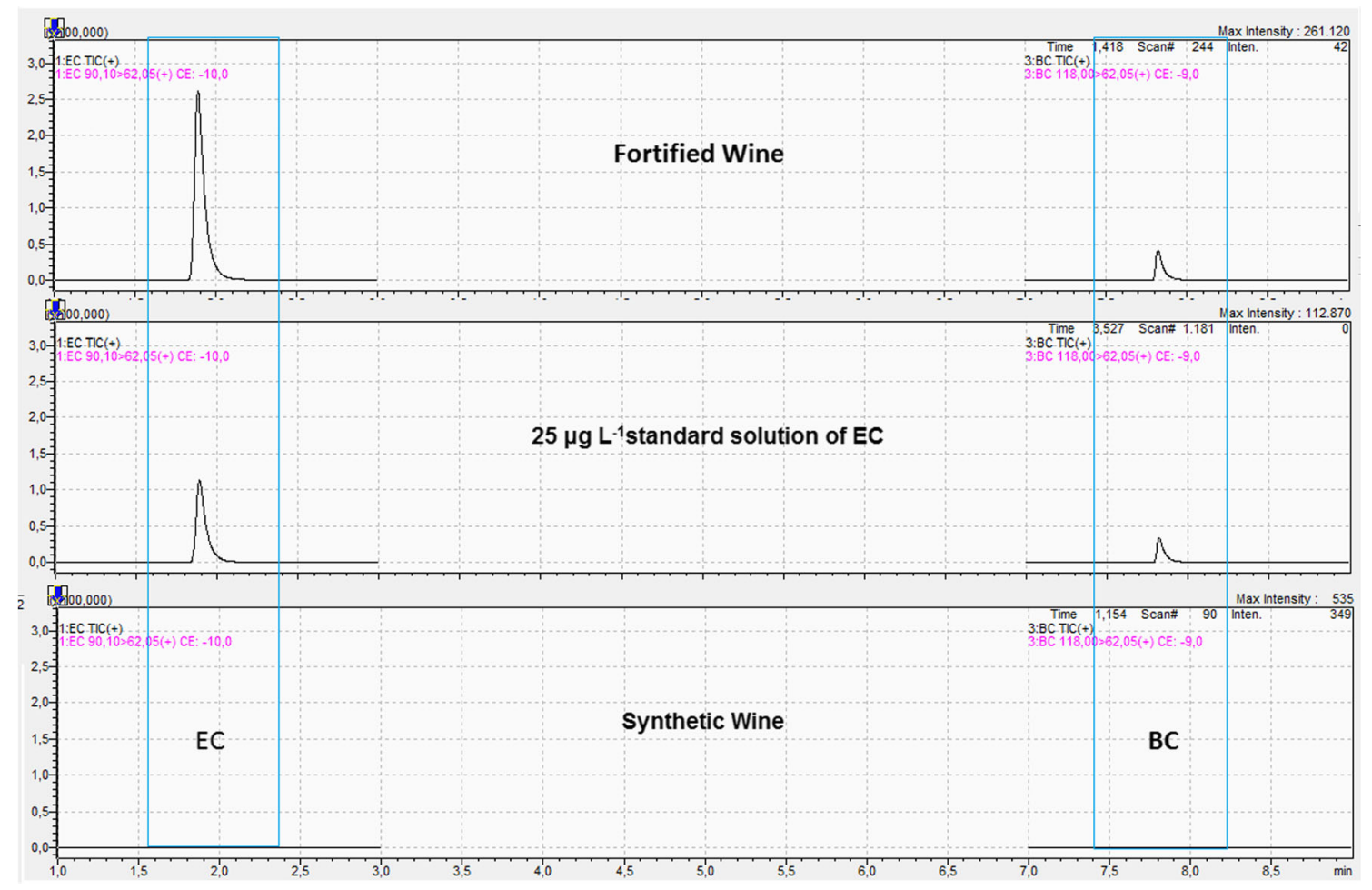

Fig. 2 Typical chromatograms of synthetic wine used to generate the calibration, $25 \mu \mathrm{g} \mathrm{L}{ }^{-1}$ standard solution and fortified wine. $E C$ ethyl carbamate, $B C$ butyl carbamate (internal standard) 
Table 3 Application of the proposed mLLE/RP-HPLC-MS/MS method for the quantification of EC in 24 fortified wines of different ages

\begin{tabular}{|c|c|c|c|}
\hline Fortified wine & Wine age & Concentration & SD \\
\hline sample & (years) & $\left(\mu \mathrm{g} \mathrm{L}^{-1}\right)$ & $(n=6)$ \\
\hline FW1 & - & 194 & 5 \\
\hline FW2 & - & 42 & 2 \\
\hline FW3 & - & 26 & 1 \\
\hline FW4 & $<1$ & 13.4 & 0.9 \\
\hline FW5 & $<1$ & 16.4 & 0.3 \\
\hline FW6 & $<1$ & 32.1 & 0.6 \\
\hline FW7 & $<1$ & 49 & 2 \\
\hline FW8 & 3 & 24 & 1 \\
\hline FW9 & 3 & 23 & 1 \\
\hline FW10 & 5 & 89 & 2 \\
\hline FW11 & 3 & 43.9 & 0.5 \\
\hline FW12 & 3 & 57 & 2 \\
\hline FW13 & 3 & 110 & 4 \\
\hline FW14 & 3 & 103 & 3 \\
\hline FW15 & 3 & 98.7 & 0.9 \\
\hline FW16 & 3 & 23 & 1 \\
\hline FW17 & 3 & 24.7 & 0.2 \\
\hline FW18 & 5 & 131 & 7 \\
\hline FW19 & 5 & 77 & 2 \\
\hline FW20 & 5 & 84 & 2 \\
\hline FW21 & 5 & 75 & 2 \\
\hline FW22 & 17 & 150 & 3 \\
\hline FW23 & 20 & 61.8 & 0.9 \\
\hline FW24 & 86 & 177 & 11 \\
\hline
\end{tabular}

$F W$ fortified wine, $S D$ standard deviation

wines, a set of 24 fortified wines were analyzed. The results are shown in Table 3. The resolution, selectivity, and precision of the obtained chromatograms and corresponding results confirm the applicability of the proposed method to quantify EC in fortified wines. The quantified concentrations varied from $23 \pm 1$ to $194 \pm 5 \mu \mathrm{g} \mathrm{L}^{-1}$, showing that the developed method covers the concentration range usually found for this compound in wines (Table 3). Despite the wide range of ages of the analyzed sample set, a direct correlation between EC values and wine age was not found. Six wines presented ethyl carbamate concentrations superior to $100 \mu \mathrm{g} \mathrm{L}^{-1}$ and 12 superior to $60 \mu \mathrm{g} \mathrm{L}^{-1}$.

\section{Conclusion}

A simple, sensitive, and eco-friendly method based on mLLE and RP-HPLC-MS/MS was successfully developed for the determination of ethyl carbamate in fortified wine samples, without resorting to derivatization. The mLLE optimization was achieved, ensuring a good compromise between sensitivity and low usage volumes. The proposed method shows good linearity, sensitivity, selectivity, precision, and accuracy. The mLLE provides a favorable extraction of EC in less than $15 \mathrm{~min}$ and a LC-MS/MS analysis in $18 \mathrm{~min}$. The method was successfully applied to determine the concentration of EC in 24 fortified wines confirming its suitability. This low-cost method is a great contribute for simplifying the EC determination in wines, for mitigation and control purposes. Future perspectives should also be focused on the simultaneous analyses of EC and its main precursors.

\section{Compliance with Ethical Standards}

Funding João M. Leça (PhD studentship), Vanda Pereira (Post Doc fellowship), and Ana C. Pereira (Post Doc fellowship) are thankful to the Agência Regional para o Desenvolvimento da Investigação Tecnologia e Inovação for the financial support through their grants in the scope of the project M1420-09-5369-FSE-000001. The financial support was given by Fundo Europeu de Desenvolvimento Regional (+ Conhecimento program, VALIMED project, MADFDR-01-0224FEDER-000006)

Conflict of Interest João M. Leça declares that he has no conflict of interest. Vanda Pereira declares that she has no conflict of interest. Ana C. Pereira declares that she has no conflict of interest. José C. Marques declares that he has no conflict of interest.

Ethical Approval This article does not contain any studies with human or animal subjects.

Informed Consent An informed consent is not applicable for the nature of this study.

\section{References}

Ajtony Z, Szoboszlai N, Bencs L, Viszket E, Mihucz VG (2013) Determination of ethyl carbamate in wine by high performance liquid chromatography. Food Chem 141:1301-1305

Alberts P, Stander MA, De Villiers A (2011) Development of a novel solid-phase extraction, LC-MS/MS method for the analysis of ethyl carbamate in alcoholic beverages: application to South African wine and spirits. Food Addit Contam 28:826-839

Anastassiades M, Lehotay SJ, Tajnbaher D, Schenck FJ (2003) Fast and easy multiresidue method employing acetonitrile extraction/ partitioning and "dispersive solid-phase extraction" for the determination of pesticide residues in produce. J. AOAC Int 86:412-431

Arena ME, Saguir FM, Manca de Nadra MC (1999) Arginine, citrulline and ornithine metabolism by lactic acid bacteria from wine. Int $\mathrm{J}$ Food Microbiol 52:155-161

Baan R et al (2007) Carcinogenicity of alcoholic beverages. Lancet Oncol 8:292-293

Bertrand A, Hitos NP (1998) Sous-Commission conventionnelle d'unification des Methodes d'analyse et d'appreciation des vins. vol 71. Office international de la vigne et du vin, Paris

Bruzzoniti MC, Checchini L, Carlo RM, Orlandini S, Rivoira L, Bubba M, (2014) QuEChERS sample preparation for the determination of pesticides and other organic residues in environmental matrices: a critical review. Anal Bioanal Chem 406(17):4089-4116

Deák E, Gyepes A, Stefanovits-Bányai É, Dernovics M (2010) Determination of ethyl carbamate in pálinka spirits by liquid 
chromatography-electrospray tandem mass spectrometry after derivatization. Food Res Int 43:2452-2455

Dong H, Guo X, Xian Y, Luo H, Wang B, Wu Y (2015) A salting outacetonitrile homogeneous extraction coupled with gas chromatography-mass spectrometry method for the simultaneous determination of thirteen N-nitrosamines in skin care cosmetics. J Chromatogr A 1422:82-88

Dong H, Xiao K (2017) Modified QuEChERS combined with ultra high performance liquid chromatography tandem mass spectrometry to determine seven biogenic amines in Chinese traditional condiment soy sauce. Food Chem 229:502-508

EFSA (2007) Opinion of the scientific panel on contaminants in the food chain on a request from the European Commission on ethyl carbamate and hydrocyanic acid in food and beverages opinion of the scientific panel on contaminants in the food chain on a request from the European Commission on ethyl carbamate and hydrocyanic acid in food and beverages. EFSA J 551:1-44

Fauhl C, Wittkowski R, (1992) Determination of ethyl carbamate in wine by GC-SIM-MS after continuous extraction with diethyl ether. J High Res Chromatogr 15(3):203-205

Hasnip S, Caputi A, Crews C, Brereton P (2004) Effects of storage time and temperature on the concentration of ethyl carbamate and its precursors in wine. Food Addit Contam 21:1155-1161

IARC (2010) Alcohol consumption and ethyl carbamate. IARC Monogr Eval Carcinog Risks Hum 96:3-1383

Jagerdeo E, Dugar S, Foster GD, Schenck H (2002) Analysis of ethyl carbamate in wines using solid-phase extraction and multidimensional gas chromatography/mass spectrometry. J Agr Food Chem 50:5797-5802

JECFA (2005) Summary and conclusions of the sixty-fourth meeting of the joint FAO/WHO expert committee on food additives, Rome, 817 February 2005

Jiao Z, Dong Y, Chen Q (2014) Ethyl carbamate in fermented beverages: presence, analytical chemistry, formation mechanism, and mitigation proposals. Compr Rev Food Sci F 13:611-626

Lachenmeier DW, Frank W, Kuballa T (2005) Application of tandem mass spectrometry combined with gas chromatography to the routine analysis of ethyl carbamate in stone-fruit spirits. Rapid Commun Mass Spectrom 19:108-112

Lachenmeier DW, Nerlich U, Kuballa T (2006) Automated determination of ethyl carbamate in stone-fruit spirits using headspace solid-phase microextraction and gas chromatography-tandem mass spectrometry. J Chromatogr A 1108:116-120

Leça JM, Pereira AC, Vieira AC, Reis MS, Marques JC (2015) Optimal design of experiments applied to headspace solid phase microextraction for the quantification of vicinal diketones in beer through gas chromatography-mass spectrometric detection. Anal Chim Acta 887:101-110

Leça JM, Pereira V, Pereira AC, Marques JC (2014) Rapid and sensitive methodology for determination of ethyl carbamate in fortified wines using microextraction by packed sorbent and gas chromatography with mass spectrometric detection. Anal Chim Acta 811:29-35

Liao Q, Li W, Luo L (2013) Ultrasound-assisted emulsificationmicroextraction for the sensitive determination of ethyl carbamate in alcoholic beverages. Anal Bioanal Chem 405:6791-6797

Lijuan W, Runhui K, Bing W, Jianjun Y, Quanhou S (2012) Direct determination of ethyl carbamate in Chinese rice wine and grape wine by ultra performance liquid chromatography-electrospray ionization tandem mass spectrometry. Chin J Chromatogr 30:903-907
Machado AMR et al (2012) Experimental design methodology to optimize the solid phase microextraction procedure prior to GC/MS determination of ethyl carbamate in samples of homemade Cachaça. Anal Lett 45:1143-1155

Matuszewski BK, Constanzer ML, Chavez-Eng CM (2003) Strategies for the assessment of matrix effect in quantitative bioanalytical methods based on HPLC-MS/MS. Anal Chem 75:3019-3030

Mo W, He H, Xu X, Huang B, Ren Y (2014) Simultaneous determination of ethyl carbamate, chloropropanols and acrylamide in fermented products, flavoring and related foods by gas chromatography-triple quadrupole mass spectrometry. Food Control 43:251-257

Moein MM, Beqqali AE, Abdel-Rehim M, (2017) Bioanalytical method development and validation: Critical concepts and strategies. J Chromatogr B1043:3-11

Perestrelo R, Petronilho S, Câmara JS, Rocha SM (2010) Comprehensive two-dimensional gas chromatography with time-of-flight mass spectrometry combined with solid phase microextraction as a powerful tool for quantification of ethyl carbamate in fortified wines. The case study of Madeira wine. J Chromatogr A 1217:3441-3445

Schmahl D, Port R, Wahrendorf J (1977) A dose-response study on urethane carcinogenesis in rats and mice. Int J Cance 19:77-80

Șengül Ü (2016) Comparing determination methods of detection and quantification limits for aflatoxin analysis in hazelnut. J Food Drug Anal 24:56-62

Stevens DF, Ough CS (1993) Ethyl carbamate formation: reaction of urea and citrulline with ethanol in wine under low to normal temperature conditions. Am J Enol Viticult 44:309-312

Taverniers I, De Loose M, Van Bockstaele E (2004) Trends in quality in the analytical laboratory. II Analytical method validation and quality assurance. Trends Anal Chem TrAC 23:535-552

Valente IM, Ramos RM, Goncalves LM, Rodrigues JA (2014) Determination of ethyl carbamate in spirits using salting-out assisted liquid-liquid extraction and high performance liquid chromatography with fluorimetric detection. Anal Methods 6:9136-9141

Vial J, Jardy A (1999) Experimental comparison of the different approaches to estimate LOD and LOQ of an HPLC method. Anal Chem 71:2672-2677

Weber JV, Sharypov VI (2009) Ethyl carbamate in foods and beverages: a review. Environ Chem Lett 7:233-247

Whiton RS, Zoecklein BW (2002) Determination of ethyl carbamate in wine by solid-phase microextraction and gas chromatography/mass spectrometry. Am J Enol Viticult 53:60-63

Xian Y, Dong H, Wu Y, Guo X, Hou X, Wang B (2016) QuEChERSbased purification method coupled to ultrahigh performance liquid chromatography-tandem mass spectrometry (UPLC-MS/MS) to determine six quaternary ammonium compounds (QACs) in dairy products. Food Chem 212:96-103

Xu X, Gao Y, Cao X, Wang X, Song G, Zhao J, Hu Y (2012) Derivatization followed by gas chromatography-mass spectrometry for quantification of ethyl carbamate in alcoholic beverages. J Sep Sci 35:804-810

Zhang J, Liu G, Zhang Y, Gao Q, Wang D, Liu H (2014) Simultaneous determination of ethyl carbamate and urea in alcoholic beverages by high-performance liquid chromatography coupled with fluorescence detection. J Agr Food Chem 62:2797-2802

Zhang Y, Zhang J (2008) Optimization of headspace solid-phase microextraction for analysis of ethyl carbamate in alcoholic beverages using a face-centered cube central composite design. Anal Chim Acta 627:212-218 